Right-dislocation in Catalan: its discourse function and counterparts in English

\author{
Laia Mayol \\ Department of Linguistics \\ University of Pennsylvania \\ 619 Williams Hall \\ 19104 Philadelphia (USA) \\ laia@babel.ling.upenn.edu
}

Keywords: Discourse, Information Packaging, Right-dislocation

Suggested running head: Right-dislocation in Catalan 


\title{
Right-dislocation in Catalan: its discourse function and counterparts in English ${ }^{1}$
}

\begin{abstract}
This paper presents a corpus study of right dislocation (RD) in Catalan and discusses crosslinguistic differences of information packaging between English and Catalan. The Catalan corpus consists of 93 RDs which have been coded according to three parameters: (1) the point where the entity in the right-dislocated constituent had appeared in the discourse, (2) consequences of eliminating the right-dislocated constituent and (3) consequences of restoring the canonical order. I argue that RD in Catalan is a means to structure information in a coherent way by displacing old information from the main clause. Three main types of RDs can be found: (1) RDs which activate an entity which was no longer accessible in the discourse and make it highly salient, while still marking its discourse-old status; (2) RDs which make explicit an implicit, never textually mentioned, referent and places it in a discourse-old information position. (3) RDs referring to entities mentioned in the previous sentence. Such RDs convey an additional meaning, some "emotional content", having to do with the expression of opposition or emphasis. Such emotional meaning can be characterized in terms of a conventional implicature. In order to analyse crosslinguistic differences, an English text and its Catalan translation have been used. The Catalan translation contained 42 instances of $\mathrm{RD}$, while the English text contained none, which shows that the two languages use different strategies to encode information packaging. The Catalan translation uses RDs mostly in cases in which the English original repeats the same phrase in two consecutive utterances and in utterances which convey contrast or opposition.
\end{abstract}

\section{Introduction}

In all languages, the same propositional content can be expressed in many different ways, as the three Catalan variants in (1) show ${ }^{2}$.

(1) a. Els nens diuen moltes mentides the children say many lies

b. De mentides, els nens en diuen molt of lies the children PART-PR say many

c. Els nens en diuen moltes, de mentides the children PART-PR say many, of lies

"Children lie a lot" 
Although truth-conditionally equivalent, these three variants are not felicitous in the same contexts. Instead, they impose different constraints on the kind of context in which they may appear and encode some non truth-conditional meaning, which has been called the 'informational component' (Vallduví 1992) or 'information packaging' (Chafe 1976). By structuring the information in a particular way, the speaker is instructing the hearer about how to process and interpret the utterance, especially in relation to the givenness status of the entities.

This paper presents a corpus study of right dislocation (RD) in Catalan, the non-canonical construction illustrated in (1c) and aims to describe its main discourse functions. I argue that RD in Catalan is a means to structure information in a coherent way by displacing old information from the main clause. I also discuss crosslinguistic differences between English and Catalan regarding information packaging and, more specifically, the use of RD. The paper is structured as follows: Section 2 gives a brief overview of different approaches of information packaging and previous studies of RD in different languages; Section 3 presents the data in which I base the study of RD in Catalan; Section 4 presents the analysis of RD in Catalan; Section 5 discusses crosslinguistic differences of information packaging in English and Catalan based on a corpus of examples in which the Catalan translation contains a RD.

\section{Background}

\subsection{Information packaging}

The term information packaging was used by Chafe (1976) for the first time to refer to the level of linguistic analysis "has to do primarily with how the message is sent and only secondarily with the message itself” (Chafe 1976). In Prince's words (Prince 1981: 224), “information-packaging in natural language reflects the sender's hypothesis about the receiver's assumptions and beliefs and strategies".

There is a great deal of terminological confusion regarding what it means to be 'new' or 'old'. Different terms have been used to refer to the same phenomena or the same terms have been used to describe different facts. For instance, the partition between new and old/given information has also been called focus-ground, focus-topic, rheme-theme, etc. However, according to Vallduví and Engdahl (1996), despite this variety, all these proposals share that they "divide the sentence into a part that anchors the sentence to the previous discourse or the hearer's 'mental world' and an informative part that makes some contribution to the discourse or the hearer's 'mental world"'. 
I review here three approaches to information packaging: First, I review the ground-focus and the topic-comment approaches, following Vallduví and Engdalh (1996) and Vallduví (1992) and, then, I discuss Vallduví and Engdalh (1996) approach.

2.1.1 Ground-focus. This approach divides the utterance into a known part (the ground) and an informative, new part (the focus) (as for instance in Sgall et. al. 1986). In English, one same sentence can have multiple different partitions (the brackets indicate the focus and the capital letters the nuclear stress within the focus):

\section{(2) a. The pipes are [RUSTY] \\ b. [The PIPES] are rusty}

A sentence like (2a) would be a felicitous answer to (3a), but not to (3b), because the word which receives the nuclear stress must be focal (that is, informative). Analogously, (2b) would be felicitous as an answer to (3b) but not to (2a).

(3) a. What about the pipes? In what condition are they?

b. I have some rust remover. Do you have any rusty things?

2.2.2 Topic-comment. In this approach, the sentence is structured in a topic (what the sentence is about, following Rienhart (1982) definition) and a comment (what the speaker says about the topic). The main problem of this approach is how to identify the topic. Reinhart (1982) and Gundel (1974) provide some tests: a NP is a topic of a sentence if it can be left-detached and preceded by as for or if this sentence is a felicitous answer to the question 'what about NP?'.

Halliday (1967), who uses theme instead of topic, defines it as the 'point of departure for the clause as a message' and requires it to be sentence initial. In the examples of (3), although all the sentences have the same truth conditions, they all have a different topic (marked in bold font):

(3). John saw the play yesterday

b. Yesterday John saw the play

c. The play John saw yesterday 
2.2.3 Vallduví and Engdahl (1996). Vallduví and Engdahl (1996) view information packaging as the "structuring of sentences by syntactic, prosodic or morphological means that arises from the need to meet the communicative demands of a particular context or discourse".

Their aim is to combine the two approaches presented above to capture all the informational distinctions present in a sentence. They use Vallduví's (1992) tripartite articulation: the sentence is divided into focus and ground, and the ground is further divided into link and tail. The focus is the actual update potential of the sentence. In contrast, the ground indicates how the information update must take place. The link indicates where the focus should go (in which file, following Heim (1983)'s File Change Semantics), and the tail how the information must be updated. A sentence may present one of the following structures: link-focus, link-focus tail, all-focus and focus-tail. The four types are illustrated in (4).

(4) a. Tell me about the people in the White House. Anything I should know?

The president [hates CHOCOLATE]

b. And what about the president? How does he feel about chocolate?

The president [HATES] chocolate

c. The president has a weakness

[He hates CHOCOLATE]

d. You shouldn't have brought chocolates for the president

[He HATES] chocolate

In English, the different ground-focus partitions are usually encoded through stress. The focus is associated with a pitch accent $\left(\mathrm{H}^{*}\right.$, in Pierrehumbert's (1980) work). Links may be marked syntactically (as in (5), where it is fronted) or intonationally (with a characteristic $\mathrm{L}+\mathrm{H}^{*}$ accent). Finally, tails are not marked in a particular way in English, apart from being deaccented.

(5) A: Where can I find the cutlery?

B: The forks are in the CUPBOARD but the knives I left in the DRAWER

In Catalan, information packaging is conveyed by syntactic means: the focus remains in its canonical position, while the ground is detached; links are left-detached and tails are rightdetached. In (6), the four informational structures are shown: (a) link-focus, (b) link-focus tail, (c) 
all-focus and (d) focus-tail. Note how all links are left-detached (appear before the verb), while tails are right-detached.
a. El president odia la xocolata the president hates the chocolate
b. El president, l' odia, la xocolata the president DO-PR hates the chocolate
c. Odia la xocolata hates the chocolate
d. L' odia, la xocolata DO-PR hates, the chocolate

\subsection{Previous approaches to right-dislocation}

Ziv and Grosz (1993) describe RDs as constructions characterized by a final non-vocative NP which is coreferential with a pronoun that appears before this NP and in the same clause, as can be seen in the schema of (7a) and the example (7b):
a. $\quad \mathrm{XPRO}_{\mathrm{i}} \mathrm{Y} \mathrm{NP}_{\mathrm{i}}$
b. I don't like them at all, the cops

RDs have not received as attention in the literature as other non-canonical constructions, since they have been considered by some authors as performance error, as 'afterthoughts'. For instance, Hyman (1975: 120) explains the presence of a RD as an afterthought, as follows:

"the speaker may forget to say something in the course of his utterance; or he may find that it is necessary to add something, because his interlocutor has not understood; or he may realize that the sentence he has just uttered is unclear or ambiguous. In all of these cases (and doubtless others), he may wish to add something after the verb-final utterance"

That is, a RD would appear when the speaker has used a pronoun and, afterwards, realizes that it may be too ambiguous or vague and, through a $\mathrm{RD}$, he makes it specific what he was referring to. Geluykens (1987) also treats RDs as repair mechanisms. He argues that RDs derive from sentences such as (8) (example 8 in Geluykens 1987). 
(8) He's got a very good bloke doing it now. I mean doing this organizing

Although (8) does not contain any $\mathrm{RD}$, he argues that RDs derive from sentences like this, in which 'I mean' indicates that the speaker is repairing or clarifying the previous sentence.

However, most recent accounts agree that most RDs are not afterthoughts. Ziv and Grosz (1993) point to three main differences between RD and afterthoughts:

1. RDs always appears at the end of the utterance, while afterthoughts can appear in other positions after the pronoun, as in (9).

(9) I met him, your brother, I mean, two weeks ago

2. RDs are always coreferential with the NP or the pronoun in the main clause, while the afterthought may contain corrections of reference, such as in (10).

(10) I met John yesterday, Bill, I mean

3. RDs and afterthoughts have different intonational patterns. RDs have a single intonation contour with no pause preceding the final NP. In contrast, afterthoughts present a distinct pause before the final NP.

Birner and Ward (1998: 146) also argue against the idea that RDs contain afterthoughts because in some instances there is only one possible referent and, thus, there is no ambiguity. They claim that RDs "represent information that has been evoked, either explicitly or implicitly in the prior discourse". However, Ziv and Grosz (1998) note that the use of RDs in English is proscribed to refer to an entity which has just been mentioned unless it adds some attributive meaning, as (11) shows.

(11) a. I took my dog to the vet yesterday

b. \# He is getting unaffordable, my dog

b'. He is getting unaffordable, the mangy old beast 
They also summarize the contexts in which it is felicitous to use a RD in English and Hebrew:

1. to refer to an implicitly focused entity, that is to an entity present in the discourse situation but not mentioned

2. to refer to entities textually evoked only when:

2a. they have not been mentioned recently in discourse

$2 b$. the referent is only implicitly, but not explicitly, in focus; that is, it is an inferable, but not directly realized, entity.

2c. the NP adds some attributive meaning, apart from referring, as (11b').

As for Catalan, as mentioned in section 2.2.3, Vallduví $(1992,1994)$ argues that RDs are tails, pieces of old information not maximally salient at the moment of utterance that establish how the new information must be updated. RDs are different from left-dislocations in that only the latter encode links, which may be contrastive and which indicate where the information must be updated. RD constructions are different from sentences with pure pronominalization in that, in the latter, there is no mention of how the information must be updated.

\section{Data}

My corpus consists of 93 naturally occurring instances containing RD in Catalan: 67 instances are transcriptions of a famous comedian's shows and the rest were taken from radio, television, press, novels or conversations ${ }^{3}$.

The data has been analyzed according to the following parameters (the percentage of instances falling in each category is indicated in parenthesis):

1. Status of the detached NP

a. PrevS: Mentioned in the previous sentence $(60.2 \%)$

b. NotPrevS: Previously mentioned, but not in the previous sentence (23.6\%)

c. NetMen: Non-textually mentioned, although may be situationally implicit (16.2\%)

2. Consequences of eliminating the right-dislocated constituent of the sentence:

a. ok: the sentence is still fully acceptable $(23.7 \%)$

b. *: the sentence is not acceptable $(47.3 \%)$

c. ?: the sentence is worse than the original, but still acceptable (29\%)

3. Consequences of restoring the canonical order:

a. ok: the sentence is still fully acceptable $(10.7 \%)$ 
b. * : the sentence is not acceptable $(47.3 \%)$

c. ?: the sentence is worse than the original, but still acceptable (42\%)

Table 1 shows the data broken down according to the first parameter (boldface indicates the highest value in each category).

\begin{tabular}{|cc|cc|cc|}
\hline \multicolumn{2}{|c|}{ Status of detached NP } & \multicolumn{2}{|c|}{ Eliminating RD } & \multicolumn{2}{c|}{ Canonical order } \\
\hline \multirow{2}{*}{ PrevS } & $\%$ & & $\%$ & & $\%$ \\
& & ok & 32.1 & ok & 1.8 \\
& & $*$ & 25 & $*$ & $\mathbf{6 0 . 7}$ \\
& & $\boldsymbol{?}$ & $\mathbf{4 2 . 9}$ & $?$ & 37.5 \\
\hline NotPrevS & 23.6 & ok & 18.2 & ok & 13.6 \\
& & $*$ & $\mathbf{7 2 . 7}$ & $*$ & 36.4 \\
& & $?$ & 9.1 & $\boldsymbol{?}$ & $\mathbf{5 0}$ \\
\hline NotMen & 16.2 & ok & 0 & ok & 40 \\
& & $*$ & $\mathbf{9 3 . 3}$ & $*$ & 13.3 \\
& & $?$ & 6.7 & $\boldsymbol{9}$ & $\mathbf{4 6 . 7}$ \\
\hline
\end{tabular}

Table 1: Catalan RD data broken down by the first parameter of analysis

\section{Data analysis: Status of the dislocated information}

The data resulting from parameter 1 supports the claim that right-dislocated elements encode discourse-old information: in $83.6 \%$ (60.2\% from 1a plus $23.6 \%$ from $1 \mathrm{~b})$ of occurrences of RDs, the detached element had been mentioned in the previous discourse. RD is a good strategy to mention old information and also to displace it from the main clause. However, it seems that the constraints Ziv and Grosz identify for the use of RD in English do not hold for Catalan. Recall that they claim that an NP cannot be right-dislocated if the entity to which it refers has been mentioned in the previous utterance, unless it adds some attributive meaning. However, most instances of RDs in Catalan belong to this category (60.2\% 1a in Table 1).

In the following sections, I analyze some examples that fall under each of the categories of parameter 1 and discuss what motivates the appearance of the RD.

\subsection{Detached NP refers to a discourse-old but not recently mentioned entity}

In $23.6 \%$ of our examples ( $1 \mathrm{~b}$ type), the RD refers to discourse-old information which had not been introduced in the previous sentence, but at some earlier point. This fits very well with 
Vallduví's definition of tail and with function (2a) of Grosz and Ziv. (12a) is an example of this situation (the fragment is translated in (12b) and the sentence with the RD is glossed in 12c):

a. Per fer règim, s'ha de tenir una especial voluntat. No com el Gallardo, que me'l trobo l'altre dia i li dic: "Com estàs?". I em diu: "Fa tres setmanes que faig règim”. Dic: “Ah, sí? I quan has perdut?”. Diu: “Tres setmanes”. I té raó. Jo tampoc en tinc, de voluntat. Quan faig règim, ho passo fatal.

b. If you are on a diet, you must have special willpower. Not like Gallardo. I met him the other day and I asked him: "How are you doing?" And he answered: "I've been on a diet for three weeks". And I said: "Really? How much have you lost". And he said: "Three weeks". And he's right. I don't have the willpower either. When I am on a diet, I have a very bad time.

c. Jo tampoc en tinc, de voluntat

I neither PART-PR have, of willpower

In this example, the RD is used to refer to an entity which had been introduced at some previous utterance. Therefore, it is a way of referring to an entity which was not accessible anymore and making it highly salient. In these cases, the RD cannot be eliminated in $72.7 \%$ of the instances, since it would not be clear to which entity the pronoun is referring. If the RD were not there in the last example, the pronoun would probably be interpreted as referring back to setmanes ('weeks'). Also, if we restore the canonical order, 50\% of the instances are still acceptable, but their degree of acceptability decreases. That is, since the entity had not been introduced in the previous utterance, it is possible to refer to it with a full NP in its canonical position. However, the sentence is less felicitous since it does not make explicit that the speaker intends to refer to a discourse-old entity. In the last example, it would not be clear that the speaker, after telling us about his conversation with a friend, intends to go back to the topic of having willpower to be on a diet. Thus, the RD accomplishes two functions: unambiguously picks the entity to which the speaker wants to refer, while marking it as a discourse-old entity.

\subsection{Detached NP had not been explicitly mentioned}

This category of RDs (1c type) would fulfil function (1) of Ziv and Grosz (1993): that is, either the referent of the NP was situationally present but never mentioned or it was inferable from another mentioned entity. (13) is an example of such a case ${ }^{4}$. 
L’oració Diga trenta y tres mereix una reflexió.

'The sentence Say thirty-three deserves some thought.'

Realment la fan.servir tant, els metges?

Really DO-PR use much, the doctors?

"Do doctors really use it that much?"

After mentioning the sentence 'Say thirty-three' (which is stereotypically used by doctors when they want to examine their patients throats), the entity 'the doctors' is directly inferable and, therefore, detachable. Since the entity to which the RD refers had not previously been mentioned, if the $\mathrm{RD}$ is eliminated, the sentence is no longer acceptable (this is the case for $93.3 \%$ of the instances in our corpus). The canonical order is, in these cases, either acceptable $(40 \%)$ or dubious $(46.7 \%)$. However, the canonical order fails to make explicit the link between the displaced entity and the situation or the other entity from which the RD is inferable.

\subsection{Detached NP had been mentioned in the previous sentence}

In most instances of our corpus (60.7\%), the detached NP refers to an entity which had been mentioned in the previous utterance of the discourse (type 1a). According to Ziv and Grosz (1993), this use is proscribed in English, unless the RD adds some attributive meaning. There are four examples in our corpus in which the RD seems to fulfil this condition or something similar condition (rather than adding attributive meaning, the RD is used to refer to the same entity using a different noun, therefore characterizing it in a different way). (14) is such an example:

(14) (during a power outage) Les famílies de sobte s'han de parlar. Mires els teus germans i tenen una altra cara.

"Suddenly, families must talk. You look at your brothers and you almost don't recognize them"

Jo què li dic, a aquest tio?

I what IO-PR say, to this guy?

"What can I say to this guy?"

In this case, the RD is a good strategy to refer back to a discourse-old entity ('your brothers') with another NP, which can provide additional meaning. In this case, it provides a humorous way to refer back to the same entity. However, this explanation does not account for the great 
majority of cases, in which the displaced entity had just been mentioned, as the example in (15) shows.

(15) A: A mi el Phil Collins em sembla una mica hortera

"I find Phil Collins a little bit tacky"

B: $\quad$ Doncs a mi m'agrada, el Phil Collins

well to me please, the Phil Collins

"Well, I like Phil Collins"

In this instance, the dislocated NP (Phil Collins) refers to an entity just mentioned in the previous sentence. The detached NP does not add any attributive meaning to the referred entity and, still, is perfectly natural. Therefore, either the attributive meaning restriction does not hold for Catalan or the notion of "attributive meaning" is different for both languages and must be redefined. Also, these RDs do not fit very well into Vallduví's notion of tail, since the RD conveys information which is salient at the moment of utterance. Moreover, this is the type of RD which seems least necessary: if the RD is removed, the sentence is still felicitous $(32.1 \%)$ or dubious $(42.9 \%)$.

However, in all examples involving a RD that refers to an entity just mentioned, the RD does indeed add some meaning, some emotional content. For instance, in the previous examples, it helps to make explicit the contrast between A and B's opinion regarding Phil Collins. The sentence would also have been felicitous only with the pronoun, but the contrast would not have been as forcefully stated. It is also worth noting that this kind of RD appears frequently in interrogative (23.2\%) and exclamative sentences (12.5\%), in which the speaker tends to express a higher degree of subjectivity. Lambrecht (1981) also claims that some examples of RD in French transmit a certain feeling of "camaraderie": a stronger link between speaker and hearer is conveyed, since the speaker is making it clear that there is some information that both know. If the RD is omitted, this link disappears.

Therefore, in Catalan, an element mentioned in the previous utterance is a candidate to be rightdislocated, not only if the RD adds some attributive meaning, but also if the speaker wants to convey some additional emotive content: emphasis, opposition or camaraderie. Unlike the other two types, this type of RD is not strictly necessary to signal how the information must be updated. However, by doing so, the speaker signals to the hearer that he wishes to communicate some extra meaning. 
This process could be thought of as calculating an implicature: the speaker could have used a simpler structure (i.e. could have omitted the RD, since the referent of the pronoun is perfectly clear), but has chosen not to do so, because he wants to convey an extra meaning 5 . More specifically, this extra meaning can be analyzed as a conventional implicatures (Potts 2004). A conventional implicature is a type of meaning coded in the lexicon or the grammar (unlike a conversational implicature) and which is logically independent from assertions. Unlike assertions, conventional implicatures cannot be explicitly denied and, unlike conversational implicatures, they cannot be cancelled (Bonami and Godard 2005). Expressives and supplements have been analyzed in terms of conventional implicatures (Potts 2004); the emotional content of rightdislocation is another good candidate. I leave the formal implementation of this idea for future research.

\section{Right-dislocation crosslinguistically: English and Catalan}

This section examines differences between English and Catalan regarding information packaging, and more specifically the use of right-dislocation. In order to analyse these differences, I use examples from the Marx Brothers radio scripts (Barson 1988) and its translation into Catalan (Barson 1989). These texts are interesting because, although they are not naturally-ocurring, they try to get as close as possible to spontaneous conversation.

In the Catalan translation, there are $42 \mathrm{RDs}$, while there are no RDs in the original English text. (16) and (17) are examples of the original in English and its translation into Catalan with a RD.

(16) GROUCHO: Your little mother will be at home at the radioCOMBATZ: I ain't no mother.

(17) GROUCHO: La teva pobra mare serà a casa amb l'orella enganxada a la ràdio... COMBATZ: No en tinc, de mare.

'No PART-PR have, of mother'

As we can see, in English the same NP ('mother') is repeated in the main clause of two consecutive utterances, while in Catalan, the translator has chosen to dislocate it in the second utterance. In the translation corpus, the NP is repeated in the English original in 30 of the 42 
examples. There are also 2 examples in which there are synonyms in the two utterances (i. e. dollars and bucks) or lexically related words (i.e. a fight and fighting).

The example of (17) is a clear example of dislocation of an NP that had just appeared in the previous sentence and which is used in an utterance in which the speaker is contradicting the presupposition previously made by his addressee (i.e. you have a mother). In the translation corpus, 31 instances of RD contained phrases just mentioned, 8 had been mentioned in some point previous of the discourses and 3 had never been explicitly mentioned. Therefore, the distribution in the translation follows quite closely the distribution of the naturally-occurring Catalan data presented in Sections 3 and 4.

One of the main differences between the two languages that can explain the different use of RD is intonation. Catalan intonation is fixed and the pitch accent always appears at the end of the sentence. In contrast, English intonation is much more flexible and the main pitch accent does not need to be located at the end of the sentence, as we can see in (18).

(18) MISS DIMPLE: Mr. Ravelli, maybe you ought to see a doctor. CHICO: I did see a doctor.

The italics in the auxiliary $d o$ indicate that it receives the main pitch accent of the utterance $\left(\mathrm{H}^{*}\right.$, following Pierrehumbert 1980) and is associated with the focus, which in this case is the positive polarity of the utterance. Since Catalan does not allow such mobility in the accent, the translator has chosen to leave the verb at the end of the main clause and right-dislocate the ground information, as shown in (19).

SENYORETA DIMPLE: Senyor Ravelli, potser hauria d'anar al metge.

$$
\begin{array}{r}
\text { CHICO: } J a \quad h i \quad \text { vaiganar, al metge. } \\
\text { already LOC-PR go-PAST, to the doctor }
\end{array}
$$

Again, in the utterance with the RD, the speaker is contradicting his addressee and the RD makes this opposition stronger.

In the translation of the fragment (20), the emotional content of RD also plays an important role. In (20), there is no explicit mark of a special information packaging. However, the translator correctly decides not to reproduce the order of the English sentence, which in Catalan would be 
infelicitous (b"') since ground information would be treated as focal. Instead, both a sentence with an RD (b) or a sentence omitting this NP (b") would be felicitous. However the two are not equivalent, the difference being that (b) is much more aggressive and implicates that Chico has not been looking for a job, while (b') is much more neutral and lacks such implicatures.

(20) a. CHICO: Well, you see, I can't afford it. I no gotta job.

b. MISS DIMPLE: Why don't you get a job?

(21) a. CHICO: Miri, és que no m'ho puc permetre. No tinc feina.

b. SENYORETA DIMPLE: I per què no en troba una, de feina? And why no PART-PR find one, of job?

b'. SENYORETA DIMPLE: I per què no en troba una?

b'. SENYORETA DIMPLE: I per què no troba una feina?

As mentioned, in most of the English text of the translation corpus, the same information was repeated in two utterances of the discourse. (22) is one of the examples in which this is not the case. The translator chose to right-dislocate a phrase which had been elided in the English original. Again the choice of this structure is related to the emotive content, since the RD helps to make the workers' complaint against their manager stronger.

(22) ASISTANT MANAGER: Boys don't get excited. You know what this hotel's been up against.

CAPTAIN: We don't care. We've got to get paid.

(23) SECRETARI DE DIRECCIÓ: Tranquils, nois, no us poseu nerviosos. Ja sabeu en quina situació econòmica es troba 1'hotel, en aquests moments. "You know which is the current financial situation of the hotel" CAP DE RECEPCIÓ:

Ens és ben igual, la situació econòmica. Volem cobrar els nostres diners. "We don't care about it, the financial situation. We want to get paid"

There is another interesting pattern that emerges from the Catalan translations. In many cases, the $\mathrm{RD}$ conveys a contrast and appears frequently where there is an opposition between two phrases: i.e. two noun phrases with the same nominal head but with a different possessor determiner. For 
instance, in (24), there is a contrast between 'his name' and 'your name', which in Catalan is conveyed by dislocating the latter phrase.

(24) CHICO: He's gonna sign a contract wit me as soon as he learns to write his name. GROUCHO: That's a good one. Who's going to sign your name?

(25) CHICO: Tan aviat com aprengui a escriure el seu nom signarà un contracte amb mi.

GROUCHO: Aquesta sí que és bona. I qui el signarà, el teu nom?

'And who DO-PR sign, your name?'

Although RDs exist in Catalan and in English, its use and frequency is not equivalent in both languages. English can use prosodic mechanisms to mark the focal information and, thus, syntactic strategies such as RD are not that frequent. In contrast, Catalan needs to dislocate ground information so that the focal information is at the end of the main clause. In the analysed cases, the translator has chosen to use a right-dislocation in Catalan to emphasize the contrast (as in the pairs (24) and (25)) or the opposition or disagreement to some previous utterance (as in the example from (16) to (23)).

\section{Conclusion}

I have shown that right-dislocations in Catalan are clearly a means to structure information in a coherent way by displacing old information from the main clause. RDs in Catalan are not as constrained as in English and they can appear in broader contexts than those described by Ziv and Grosz (1993). We can find three main kinds of NPs in the detached phrase, which have different discourse functions:

(1) NPs referring to an entity mentioned some utterances back. In this case, the RD is a necessary strategy to accomplish two tasks: to activate an entity which was not accessible anymore and to make it highly salient, while still marking its discourse-old status.

(2) NPs referring to entities never textually mentioned, but which were implicitly present in the situation. As in (1), the RD also has a twofold function: it makes explicit the implicit referent and it places it in a discourse-old information position.

(3) NPs referring to entities mentioned in the previous sentence. In Catalan, most cases of RD fall under this category and only a small part add some attributive meaning. However, such RDs do convey an additional meaning, some "emotional content", having to do mainly with expression of 
opposition or emphasis. Such emotional content can be analysed in terms of a conventional implicature.

Crosslinguistically, although RDs are possible both in Catalan and English, they do not appear with the same frequency, since Catalan uses mainly syntax to express information structure, while English uses prosody. In a translation corpus, many examples were found in which the Catalan translation contained a RD, while the English original contained none. RDs appeared in Catalan translations especially in cases in which the utterance expressed contrast or contradicted some previous utterance.

\section{References}

Barson, M. (ed) 1988. Flywheel, Shyster, and Flywheel. The Marx Brothers lost radio show. New York: Pantheon Books.

Barson, M. (ed) 1989. Groucho i Chico, advocats: els guions radiofònics dels germans Marx. Translation by Màrius Serra. Barcelona: Columna.

Birner, B. and Ward, G. 1998. Information status and noncanonical word order in English. Amsterdam/Philadelphia: John Benjamins.

Bonami, O. and Godard. D. 2005. "Les adverbes évaluatifs dans une approche multidimensionelle du sens". In Questions de Classification en Linguistique: Méthodes et Descriptions, I. Choi-Jonin, M. Bras, A. Dagnac and M. Rouquier (eds), 19-37. Berne: Peter Lang.

Chafe, W. 1976. "Giveness, contrastiveness, definiteness, subjects, topics, and point of view”. In Subject and topic, C. Li (ed), 25-55. New York: Academic Press.

Geluykens, R. 1987. “Tails (Right-dislocations) as a repair mechanism in English conversation”. In Getting one's word into line, J. Nuyts and G. de Schutter (eds), 119-129. Dordrecht: Foris.

Gundel, J. 1974. The role of topic and comment in linguistic theory. Ph.D. Dissertation, University of Texas.

Gundel, J., Hedberg N. and Zacharski R. 1989. "Givenness, implicature, and demonstrative expressions in English discourse". Proceedings of the Chicago Linguistics Society: 89-103.

Halliday, M. 1967. "Notes on transitivity and theme in English. Part 2". Journal of Linguistics 3: 199-244. 
Heim, I. 1983. "File change semantics and the theory of definiteness". In Meaning, use, and the interpretation of language, R. Bauerle, C. Schwarze, and A. von Stechow (eds). Berlin: Walter de Gruyter.

Hyman, L. 1975. "On the change from SOV to SVO. Evidence from Niger-Congo". In Word order and word order change, C. Li (ed), 115-147. Austin: University of Texas Press.

Lambrecht, K. 1981. Topic, antitopic and verb agreement in non-standard French. Amsterdam/Philadelphia: Benjamins.

Mayol, L. 2002. La dislocació a la dreta en català i anglès. Senior thesis. Universitat Pompeu Fabra. Available on the WWW : <http://www.ling.upenn.edu/ laia/papers/dd.pdf $>$, accessed January 2007.

Pierrehumbert, J. 1980. The Phonology and Phonetics of English Intonation. Ph.D. dissertation, MIT.

Potts, C. 2004. The Logic of Conventional Implicature. Oxford University Press.

Prince, E.F. 1981. "Toward a taxonomy of given/new information". In Radical pragmatics, P. Cole (ed), 233-255. New York: Academic Press.

Reinhart, T. 1982. "Pragmatics and linguistics: An analysis of sentence topics". Philosophica 27: 53-94

Sgall, P., Hajicová, E. and J. Panevová. 1986. The meaning of the sentence in its semantic and pragmatic aspects. Dordrecht: Reidel.

Vallduví, E. 1992. "The Informational Component" Ph.D. dissertation, University of Pennsylvania.

Vallduví, E. 1994. "Detachment in Catalan and information packaging”. Journal of Pragmatics 22: $573-601$.

Vallduví, E. and Engdahl, E. 1996. “The linguistic realization of information packaging”. Linguistics 34, 459-519.

Ziv, Y. and Grosz B. 1993. "Right Dislocation and Attentional State". In The Proceedings of the Ninth Annual Conference Ben Gurion University of the Negev Buchalla, R. and Mittwoch A. (eds), 184-199. Jerusalem: Akademon.

\footnotetext{
${ }^{1}$ I wish to thank Enric Vallduví for advice and the audiences at SPRIK Conference (Oslo, June 2006), the University of Pennsylvania and the Universitat Pompeu Fabra for many useful comments. I thank Catherine Lai for proof-reading a draft of this paper.

${ }^{2}$ I use the following abbreviations: PART-PR (partitive clitic pronoun), DO-PR (direct object clitic pronoun), IO-PR (indirect object clitic pronoun) and LOC-PR (locative pronoun clitic).

${ }^{3}$ The full corpus is available at the appendix of Mayol (2002)
} 
${ }^{4}$ There is no clitic in the main clause because Catalan has no subject clitics. However, (3) has a clearly different intonation pattern than a sentence with a postverbal subject, marked in written with the comma.

${ }^{5}$ Gundel et. al. (1990) also invoke implicatures to explain unexpected uses of referring expressions: i.e. definite noun phrase used in situations where the referent was in focus and a pronoun would have been sufficient. 